\title{
A Twist in the Song: Retracing Myth and Dante's Poem in Heavy Metal Music
}

\section{Un rizo en la canción: Del mito al poema de Dante en el Heavy Metal}

\author{
Manuel Botero Camacho \\ Assistant Professor \\ (Complutense University of Madrid) \\ Nuria Picón del Campo \\ Graduated in English Studies at the UCM \\ (Complutense University of Madrid)
}

Reception date: 27 November 2016

Review date: 28 December 2016

To cite this article: Botero Camacho, M. and Picón del Campo, N. (2017): A Twist in the Song: Retracing Myth and Dante's Poem in Heavy Metal Music, Icono 14, volumen 15 (1), pp. 166-185. doi: 10.7195/ri14.v15i1.1013 


\section{Abstract}

The study of music is gathering strength in the academic world although there are some unexplored elements to be contemplated in this emerging field. As mixed media, music enjoys the power of melody and that of lyrics. Its power to reach any social nook makes music a gigantic cultural tool with the force of sending any kind of message in dynamically and effectively. The way in which heavy metal - and especially its symphonic branch - plays with this duality of melody and text, together with the mythological content from which lyrics often feed, makes this genre an essential step in intermedial research. This paper focuses on symphonic heavy metal as a source of mythological knowledge that helps build a bridge linking popular music with one of the most celebrated literary works of all times: The Divine Comedy. On the one hand, the paper demonstrates the social importance of popular music while showing how the field which has not escaped the influence of the Dantesque world that permeates many symbolic realms in the Western world.

Key Words: Heavy Metal - Symphonic Metal - Myth - Dante - Legend - Holy Grail Ground \& Figure

\section{Resumen}

El estudio de la música cobra fuerza en el mundo académico si bien quedan elementos por contemplar en este nuevo campo. Como medio híbrido, la música disfruta del poder de la melodía a la par que de la letra. Su poder de llegar a cualquier nicho social convierte a la música en una enorme herramienta cultural con la fuerza de enviar cualquier tipo de mensaje de manera dinámica y efectiva. La manera en la que el Heavy Metal - y especialmente su rama sinfónica - juega con esta dualidad de la melodía y del texto, junto con el contenido mitológico del que se nutren con frecuencia sus letras convierte a este género en un paso esencial para la investigación intermedial. Este artículo se centra en el estudio del heavy metal sinfónico como una fuente de conocimiento mitológico que posibilita un puente entre la música popular y una de las obras literarias más célebres de todos los tiempos: la Divina Comedia. Por un lado, el artículo demuestra la importancia social de la música popular al tiempo que muestra cómo el género no ha escapado la influencia del mundo dantesco que permea los entornos simbólicos del mundo occidental.

Palabras clave: Heavy Metal - Metal Sinfónico - Mito - Dante - Leyenda - Santo Grial - Fondo \& Forma 
“When I reminisce about all those years of tribulation, I mostly remember our songs. We died, and our blood seeped away on the battlefields; but our songs survived, together with those of us that returned. And as they too will die one day, our songs will live on, and will be sung by our children, And by our children's children. This is how we will be remembered. This is who we were." ("Epilogue" by Eluveitie)

\section{Introduction}

Music as a vehicle to culture is a subject which has gradually grown in interest amid academia and among different fields of research, giving birth to an immense quantity of articles and debates (Bennett, 1989; Wright, 1992; Berger \& Del Negro, 2004). Music is simultaneously one of the most important elements in the popular tradition and also one that retains important references in terms of culture and mythology. This interest has mainly revolved around classical music (Van Boer, 2012; Charles et al., 2013), targeting it as the referential musical genre to study mythological influences and putting other contemporary genres aside, wrongly branding them as minor forms of art. This paper argues that the differences between classical and popular music do not correspond to a discussion on more or less quality, but rather to new approaches and points of view and, in fact, new audiences.

In the same way culture and its means of expression evolve over time, so does the format in which popular culture make its way through society. However, amid all the different vehicles that culture uses, music, once again, makes a difference, not only for its unique form but also because of its adaptability and permeation to changing contexts. Being already a malleable element, able to reach different types of listeners, music has been able to lead the technological race by finding new ways in which to present itself, taking advantage of every single technological improvement. From vinyl records which required huge record-players, to $\mathrm{mp} 3$ and mp4 formats, whose digital format has made it possible to listen to music everywhere. Music is more than ever present in our daily life; constantly expanding towards the demands of the most varied social groups and adapting itself to their ideological and cultural frames of mind. Among these different musical genres 


\section{MONOGRÁFICO}

with a basis on mythology as a source, heavy metal music and, more precisely, symphonic heavy metal, stands out.

Symphonic metal assembles all the typical characteristics of heavy metal together with elements from classical music, which may include choirs, symphonic instruments or an orchestra. These features produce a particular effect upon the mythological content of the songs, mixing form and content and breaking their separating barrier in order to transform them into a whole unit necessary to successfully experience the narrative of the song. The difference between ground and figure is inspired in the concept of Escher depicted in works like Whirlpools or in Day and night; Sky and water I or the Mosaics I and II, to name a few, and explained by Douglas Hofstadter in the following text:

When a figure or «positive space» (e.g., a human form, or a letter, or a still life) is drawn inside a frame, an unavoidable consequence is that its complementary shape - also called the «ground», or «background», or «negative space» - has also been drawn. (1979: 67)

Hofstadter's proposal includes three multidisciplinary voices that make his work relevant to this particular research. Regardless of the content, it provides a research tool - what he terms "repeated isomorphism", which deals with realities that require a non-lineal study. This tool helps 'orchestrate' different points of view for the same subject matter, and provides a helical method that allows the comprehension of a certain topic from different approaches and fields of study.

Heavy metal maintains the original nature of the troubadour in two senses; it acts as a source of knowledge for people, since, as a part of mass culture, it is able to reach a wide number of listeners with an attractive and attainable form. On the other hand, it appeals to the most immediate nature of the troubadour, creating a certain atmosphere which fosters the experience of the myth. These characteristics are an advantage over other genres, since the song transcends its primary nature to become a dramatic interpretation of the lyrics, not unlike opera. In a reciprocal relation, the song feeds upon the mythological content, contributing to 
its preservation; myth is also nourished, since this new treatment gives it greater force and presence in contemporary society, sometimes from a completely new point of view.

Hofstadter highlights Bach and his music as the musical evidence for the "Figure and Ground Theory". He argues that those classical pieces of music include a complex form where both the main melody and the accompaniment play a crucial role in the development of the song; where one cannot be understood without the other.

One may also look for figures and grounds in music. One analogue is the distinction between melody and accompaniment - for the melody is always in the forefront of our attention, and the accompaniment is subsidiary, in some sense. Therefore it is surprising when we find, in the lower lines of piece of music, recognizable melodies. This does not happen too often in post-baroque music. Usually, the harmonies are not thought of as foreground. But in baroque music - in Bach above all - the distinct lines, whether high or low or in between, all act as "figures". (Hofstadter, 1979: 70)

However, in spite of Hofstadter's dismissal of post-baroque music (he does not address this feature in other contexts), the theory can be applied to more contemporary genres, especially to the concrete one this essay is dealing with. In fact, medieval music and mythological contexts are usually conceived as a fixed unit. In the case we deal with in this paper, it may come closer to the Renaissance, for it creates much more interaction between the harmony and the instruments and whether intentionally or not - it actually uses the possibilities within Hofstadter's proposal.

Symphonic metal systematically revolves around mythological content, although the treatment of the myths varies among the different groups and countries. Even though, several bands are named here as reference, in order to exemplify the approach from both the North-American and the European perspective, four have been chosen as paradigms: Symphony $\mathrm{X}$ and Iced Earth from the United States, Blind Guardian and Grave Digger, from Germany. Their production will be 
briefly analyzed based on the representation and contribution to the study of myth and in order to demonstrate the interactive relationship between heavy metal and mythology, in particular with regards to the presence of Dante's Divine Comedy in this genre.

\section{Methodology}

The methodology used for this investigation focuses predominantly in the review of existing literature, in the fields of musicology, folklore, mythology and literature, in combination with the analysis of an extensive body of works of music belonging to the heavy metal genre. The study of these works has integrated the interpretation of elements belonging to the sound track (i.e. rhythm, sound effects...) with a close reading of the songs' lyrics.

The research is aimed at highlighting how the mythical realities of Western tradition, passed on in canonical texts such as Dante's Divine Comedy, as well as in legends belonging to folklore, have been reclaimed, transformed, and adapted to the contexts of contemporary culture and its globalized audiences, in part thanks to technological advancements. To such purpose, a brief survey of theoretical notions in the field of music, based on previous work by Douglas Hofstadter is presented in the introduction. This is followed by textual analysis of the works of the proposed bands which serves to illustrate how myth is used and reshaped by each of them. As mentioned, we have reduced the examples to symphonic metal bands in North-America and Europe, including Grave Digger, Symphony X, Blind Guardian and Avantasia.

The analysis of the treatment of myth by these bands is followed by an overview centered on the influence of Dante's Divine Comedy over them, as well as over other bands belonging to other contexts and genres. The heavily referential works of Symphony $\mathrm{X}$ and Sepultura stand out as the most significant examples of the process of mythical recycling and adaptation. Finally, the different perspectives resulting from our interpretation are synthesized in relation to their implications on the revision of tradition as part of contemporary culture and emerging new media. 


\section{Development}

\subsection{Myth in contemporary music compositions}

Grave Digger is a German band whose recent albums have been dedicated to particular myths, their compositions becoming a tribute to the myths they sing about. Their Middle Ages Trilogy is composed by three different albums: Tunes of War (1996), about the Scotland struggle for independence, Knights of the Cross (1998), which deals with the history and legend of the Knights Templar, and Excalibur (1999), which relates King Arthur's legend. Each album is organized in the same way, structured in different chapters each corresponding to certain events or characters. All of them contain a brief text apart from the lyrics which explains the content, providing all kinds of historical information.

One of the differences Grave Digger introduces, as a symphonic metal group, is the use of sound elements that bring the story to life, a fact that sets them closer to the purest role as troubadours. They include all kinds of components, from choirs in Latin to create a church-like illusion, to different wind instruments that contribute to the epic atmosphere. Thus, to illustrate "The Battle of Bannockburn" (1998, track 12), a song included in Knights of the Cross, horse-like guitar and percussion sounds convey the feeling of going into battle. Each character is given a voice and becomes narrator of their own songs. Grave Digger exposes the story as it is, and yet their contribution is immense, for they are giving life and force to a set of myths which are part of the historical literary cannon, and they are doing it in a context where any reference of such historical value would not be expected, thus fusing legend and history. The stories are retold emphasizing their socializing contents, revitalizing them once again in a hybrid form of storytelling that appropriates and fuses myth and history.

Similarly, Symphony X contributes to add new layers to mythical stories, endowing them with additional semiotic relevance. The album The Odyssey released in 2002, includes references to Homer's work as well as links them to other myths. This is the case of "Incantations of the Apprentice", the third song in the album, which is related to the story of the Sorcerer's Apprentice. "Accolade II" is another 


\section{MONOGRÁFICO}

example; an epic poem based on a mix of Braveheart and Robin Hood. The second part of the album is completely dedicated to The Odyssey, divided into different songs which are allusions to some of the most remarkable episodes in the poem. Their work here is not so different from Grave Digger's in the sense that they just revive the voices of those characters, however, they create a very interesting web of myths, relating Medieval and Renaissance motifs with Greek literature. In 2007 they released Paradise Lost, which introduces the listener to one of the most celebrated works of literature, and adapts the text to a contemporary perspective, approaching it in a dark tone, typical of the metal music genre. It includes songs such as "Eve of Seduction", as well as obscure settings and situations, with Adam giving voice to tormented humankind: "Can it be true/ Why can't you see I'm burning for you/ There's no disguise in my desires/ What can I do?" (Symphony X, 2007, track 6). The aperture, "0culus ex Inferni" (Symphony X, 2007, track 1), mixes guitar riffs with choirs, trumpets, and different symphonic instruments creating the proper atmosphere in anticipation to what it is to be expected. The entire album offers connections between traditional myths and their new lives in contemporary popular culture.

Iced Earth is another group whose contributions are based on reinventing myth. In 2001 their sixth album, Horror Show, which includes a set of songs dedicated to classic figures of the Gothic tradition. Among them, "Jack" (track 3), based on the character of Jack the Ripper, "Jekyll \& Hyde" (track 6), "Frankenstein" (track 9) or "Dracula" (track 10), to name a few. They give voices to those characters, whose stories are known throughout the world, but also a new perspective. "Jack", for instance, depicts a proud murderer who reaffirms himself and is not ashamed of his deeds. "Dracula" features a fallen warrior who questions his beliefs and regrets his destiny

Do you believe in love?

Do you believe in destiny?

True love may come only once in a thousand lifetimes...

I too have loved... they took her from me.

I prayed for her soul... I prayed for her peace (from "Dracula" Iced Earth, 2001, track 10) 
Blind Guardian also proposes a complex interpretation of myths. After shy attempts to retell legend, such as "The Bard's Song" (tracks 7 \& 8) included in Somewhere Far Beyond (1992) or "Mordred's Song" (track 5) included in Imaginations from the Other Side (1995), the group ventured into more committed projects. Albums such as Nightfall in Middle Earth (1998), which explores Tolkien's Silmarillion, or A Night at the Opera (2002), deals with myths, legends and history. A Twist in the Myth (2006) owns to its title to an utterly new reading of different and varied myths, ranging from Peter Pan to the Holy Grail or Ulysses. The lyrics of "Fly", for instance, explore the story of Peter Pan giving the story new perspectives: "Step out of line/ And I'll teach you how to fly/ Then away we'll go/ Leave your mark land of mine" (Blind Guardian, 2006, track 4). The way in which Blind Guardian approaches the story creates a new assessment of the tale, with Peter Pan's innocence, flying away into fairyland. Along the same lines, "All the King's Horses" opens a new interpretation for the well-known Holy Grail myth and its endless quest. The stories and myths used in this album benefit mutually, for they are not only rescued from oblivion, but also reloaded with new values. Each song is not necessarily isolated to a single myth, but rather a combination of different elements from different sources into a new aesthetics: "All the king's horses/ And all the king's men/ They've failed to damn the flood/ They've failed to find the Grail/ Talisien, old friend of mine/ Sing my song" (Blind Guardian, 2006, track 12). In this line, the allusion to the Welsh poet Taliesin plays an important role, serving as a flame aimed to relight his presence and cultural importance as well as contributing to the mystery and uncertainty of the song. Blind Guardian manipulates myths of enshrined traditions in order to create a whole new re-invented corpus.

The group Avantasia and their Metal Opera (2001-2002), a concept album divided into two main parts, represents a milestone in symphonic metal history. Avantasia follows Blind Guardian's path as they select certain elements from different traditions, but the band goes one step further. The journey of the main character through a world of mystery is depicted, giving birth to an epic narration nourished by some of the most iconic motifs of the mythological tradition. In "Serpents in Paradise" (Avantasia, 2001, track 3), for example, Milton's work is again the source of inspiration, as well as the figure of Peter Pan in "Neverland" (Avantasia, 2002, track 6). Tobias Sammet, singer and producer of this project, gathered some of the 
most famous and renowned musicians within the heavy metal genre to proclaim what this essay also defends: the importance and power of such musical genre, not only in terms of music and experimentation, but also in terms of tradition and prevalence.

Avantasia's work can be compared to another European band, from Italy, formerly known as Rhapsody nowadays re-named Rhapsody of Fire. They have also created their own narrative based on mythological archetypes from medieval sagas, composing a series of five albums around the same storyline. Finally, they released the compilation album Tales from the Emerald Sword Saga (2004), which gathers selected songs from their previous works -that already stood out for the weight of their mythological content, also created by the band- to create a unified epic narration. They renewed their own mythological material for a complete story that narrates different episodes that maintain the spirit of the aforementioned bands in terms of creating an atmosphere where the listener is able to become a part of the interactivity of the song. Thus, war-like tones will sound in songs like "Dawn of Victory" (track 9) or "Rain of a Thousand Flames" (track 12), while in songs like "The Village of the Dwarves" the instruments and devices employed by the band, such as the sound of a waterfall, will transport the listeners to gentler settings, adapting it to the lyrics: "The dance of fire and wind/ And the stories about old kings/ Are pleasing our brave lords/ Down in the village of dwarves" (Rhapsody, 2000, track 11). Although Tales from the Emerald Sword Saga is a compilation album, which usually includes just the greatest hits of a band, there is a latent story within the different songs, a fact that suggests that the band is doing what other musicians have done with traditional mythology: claiming traditional folklore and integrating it in their music to inject new life, importance and force that established stories have.

This section has taken into consideration the reciprocal relationship between myth and symphonic heavy metal, tracing the basic patterns that repeat themselves throughout the history of myth. Other symphonic bands, such as Visions of Atlantis or Epica, include the mythological intention in their own names. Other bands, such as Nightwish also offers songs that refer to myths such as "Elvenpath" (1997, track 1) in a recurrent phenomenon which constantly renovates 
itself with the inclusion of contemporary sources, such as George R.R. Martin's Game of Thrones in Blind Guardian's "War of the Thrones" (2010, track 8). This song is dedicated to one of the most celebrated characters of the saga, Jon Snow. Another example is Tolkien's work, mentioned above. In 2000, probably as a logical conclusion to these explorations, singer Hansi Kürsch (Blind Guardian) and guitarist Jon Schaffer (Iced Earth), joined intellects and talents in the project Demons and Wizards, bringing together the North-American and European points of view in two albums that, once again, revisit myth and legend.

As shown in this section, symphonic heavy metal drinks from multiple mythological fountains. The cases presented cover an ample range of cultures, ages and regions. However, some myths are more recurrent than others, chosen by their cultural proximity, their archetypical value or even their settings and environments. One of such myths is the paradigm we find in Dante's Divine Comedy.

\subsection{Dante`s myth as paradigm}

Dante's poem is a source of inspiration for several bands, from individual tracks, such as Iron Maiden's "Purgatory" (1981, track 9) or Symphony X's "Inferno (Unleash the Fire)" (2002, track 1), to albums completely dedicated to the myth, like Sepultura's Dante XXI (2006) and Symphony X's Underworld (2015). Each of them contribute, one way or another, to the nutrition of this celebrated work. The reading of the poem has developed 'collective imaginaries' dyed with tradition; the Comedy is a classic text, a text which has emphatically infiltrated into the collective unconscious.

The idea of hell within the Western world is basically the one versified by Dante. Without going any further, the introduction to the purgatory, not invented but popularized by Dante, in the secular faith is surprising, for it is a place which lacks Scriptural sources, but it has been defined, delimited and installed as an indelible print in the collective unconscious. These effective and evident appropriations appear across the widest artistic scenarios, including Heavy metal music. 


\section{MONOGRÁFICO}

Dante's Divine Comedy has become a site of rewriting and reinvention partly due to the thematic elements and hermetic symbology it represents. There is also a coincidence in terms of the structures. The signifier form is a way of poetically approaching reality, moving aside from the linearity meaning referent. There are two reasons why symbology must be studied in a different way: "Primero, porque el simbolismo no es del orden de lo racional y porque, al presentarse de manera conceptual, inevitablemente se le falsea. En segundo lugar, porque no se trata de una doctrina o de un método, sino de un arte de vivir, de una manera de ver."(De Champeaux \& Sterckx, 1985: 11) ${ }^{1}$

Therefore the initiative of studying symbology is understood from a non-lineal proposal as outlined. Returning to the idea of ground and figure, in The Divine Comedy, it can be noticed the existence of "a meticulous external symmetry that matches with the organized internal architecture" (González Ruiz 1956: 25). The poem has an internal symmetry which connects the contents with the way in which they are described. It is written in triplets and there are three different environments; the constellations reflect the different events within the text, for instance. Music develops in the same way, using that symmetry between instruments, voices and narration. Having said that, this game of levels -once again, intentional or not- offers multiple interpretative possibilities that create a new reading while it is played and sung, for it must be taken into account that Dante's work is lyrical and, therefore, closer to music than to prose.

Iron Maiden, an English heavy metal band, is one of the first examples to prove that references to Dante's work, however subtly, are present in heavy metal music. In their second album, Killers (1981) they included a song called "Purgatory". As explained before, the concept of purgatory is based on Dante's depiction, a place designed as a mountain where the effort and sacrifice spent during the ascension is understood as an expiation and purification. In the song, we find a voice that is trapped in this road between hell and paradise:

Over clouds my mind will fly, forever now I can't think why.

My body tries to leave my soul.

Or is it me, I just don't know. 
Memories rising from the past, the future's shadow overcast.

Something's clutching at my head, through the darkness I'll be led.

(Iron Maiden, 1981, track 3 B-side)

The protagonist's bewilderment can be somehow compared to Dante's. A character lost between two dimensions, lost in the dark, it is an archetypical situation which repeats itself throughout the history of heavy metal, and it usually shares common features with the scenarios described in the Divine Comedy. The struggle of a character trapped between the light and the shadows, the good and the evil, hell and paradise, a character stuck in a contemporary purgatory. Another common Dantesque motif in this genre can be understood as one of the immediate consequences of the previously mentioned, the descent into hell. Symphony X's "Inferno (Unleash the Fire)" offers one of the most recurrent scenarios in heavy metal, which is a voice fallen into the depths of hell: "Forces they're oppressing me/ Lords of mediocrity/ An iron will shall break the still/ Some will rise and some will fall/ Oh... yes, we ride through stormy skies of Fire" (Symphony X, 2002, track 1).

The song belongs to an album previously analyzed, The Odyssey, a fact that facilitates establishing a stronger link to Dante. The most evident hint is hidden in the title and part of the content of the song. The choice of the word 'inferno' instead of, Tartarus, Underworld or even hell, suggests an allusion to Dante's Inferno per se, and the situation in which the main voice finds itself may be relatable to some of Dante's reaction during his journey; that said, the fact that this song is included in an album entirely devoted to The Odyssey enables another reference to the Comedy through one of the most well-known characters in the history of literature, Ulysses. The XXVI canto of Dante's poem is also known as the "Ulysses canto", for it is the display of the Greek hero's penance (2008: 154-159). In much the same way this chapter serves as a brief summary of Ulysses' last adventures, the song works as an overture for the misfortunes of a wicked man. The character in the song is depicted in a way that reminds Dante's portrayal of Ulysses - both are approached as characters whose extreme brilliance doomed them, making them fall near the supreme evil. 


\section{MONOGRÁFICO}

The references to the Divine Comedy are countless, and to analyze each form in which they occur within the heavy metal course would be impossible. That is the reason why, after presenting a couple of the minor allusions that can be found, it is convenient to go in depth into some of the greatest tributes to Dante's poem. To that end, two different groups will be taken into account: Sepultura, as a representative of thrash metal and, once again, Symphony $\mathrm{X}$, so as not to break with the main line of this article, which is symphonic heavy metal.

Sepultura published Dante XXI in 2006. The album is divided into three different parts, which correspond to the episodes in the poem; it is a musical journey following Dante's steps. The album opens with an instrumental song which lays down the proper atmosphere to begin the passage, with a mixture of exotic sounds and a voice in off. In the second song, "Dark Wood of Error", there is a character utterly lost in the darkness, that is, a character that just landed in hell:

I've lost my way

In a dark wood of error

In a crisis, inside deep terror

With fear in my mind, I spot a light

They're coming after me

Can't reach the light

Three beasts blocked the path

That leads the way to my life

The beast from the UK

The beast from the US

(Sepultura, 2006, track 2)

The similarities that can be found between the song and the poem are interesting, for one of the most characteristics features of the Comedy is the criticism towards political matters within the Italian context. The beasts mentioned in the song are depicted as elements aimed "to solve the problems in the world" but which only function as oppressors. The journey through hell continues with "Convicted in Life", "City of Dis", "False" and "Fighting 0n", where the episode ends just as Dante's, with a determined and unstoppable character, resolute to finish what he began: 
We don't stop, we keep fighting on

From the first birth of life

Till our final last breath

You never thought that you could make it

But we carry our own

(Sepultura, 2006, track 6)

The next four songs, "0stia", "Buried Words", "Nuclear Seven" and "Repeating the Horror" correspond to the Purgatory in the Comedy, and the approach is the same.

The skies are open before me

The crowd of souls in sudden flight

Hoping for prayers in the world

Late repentant, no stain from hell

(Sepultura, 2006, track 8)

The character can be identified entirely as a contemporary Dante, for the band adapts the original tone of the poem to the contemporary worries of the social collective, which include politics, "Those fools are the ones we vote for/ The kings and rules of negligence/ Taking a nation to lead in decay" (Sepultura, 2006, track 8), personal crisis related to the established values and moral, "My head keep spinning with the shit that you said/ You even had me get down on my knees/ Praying for something that I never believed"(Sepultura, 2006, track 9) and even the postmodern feeling of not belonging to a destroyed society: "Atomic shit to fuck with our heads/ In this new world, that's full of crack/ Our children cry, they're lost and mad/ We're lost!" (Sepultura, 2006, track 10). The approach to the Divine Comedy in this case is the same that can be found in the bands commented in the beginning of this research: that of nourishment from a work of literature already very present in our society, giving it contemporary brush-strokes so its nature renovates and adapts. It contributes to one of the main characteristics of Dante's poem, which is immortality. 


\section{MONOGRÁFICO}

Symphony X's approach works in the same way but offers a slight difference. In 2015 they released Underworld, an album that, despite not offering references as direct as Dante XXI, revolves around the Dantesque experience in hell. The album also opens with an instrumental song aimed to place the listener in situation choirs, symphonic instruments and a tense melody introduce the listener into the depths of the Inferno. The next song has double literary valor, for it is not only the first steps into hell, "From the skies, across the sea of lies/ To the dungeons of the damned/ Scorching winds blazing thunderclouds raging/ Here I make my stand" (Symphony X, 2015, track 2), but also plays with Poe's famous "nevermore", which gives the song its name and it is repeated throughout. To emphasize the Dantesque atmosphere even more, the song includes the quote "Abandon hope all who enter here", one of the most famous sentences of the Comedy, which, in turn, has become the most famous representation of the gates of hell.

The references to Dante's poems are constant; from all the sinners and the flame Dante speaks to in "Underworld", to Dante's feelings and emotions related to the aim of his trip, "I've come undone/ Fearing things unseen/ Can I mend this broken dream" (2015, track 3), Symphony X provides the listeners with a whole new reading of the Divine Comedy which, although it does not lose its natural origin, allows the reader to build a personal interpretation of the text.

The most innovative aspect introduced by Symphony X has a metaliterary nature. The last song in the album, "Legend", works as an ending point which contributes, even more, to the spirit of perpetuity that characterized both the song, as a musical element, and the text:

The rise and fall

Although I fight like hell, there's just no certainty.

My battlefield lay scarred with empty victories.

Running from the past, from a lifetime of lies.

But the legend never dies...

The legend never dies...

(Symphony X, 2015, track 11) 


\section{Conclusion}

The myth of the Divine Comedy will never die thanks to its immanent presence in several social and cultural aspects. Music can emphasize even more this power. Music is not only a vehicle; it is a device and a cultural weapon that carries across any kind of message to any kind of audience in a very effective way.

Dante's masterpiece has prevailed for seven hundred years, surviving all scientific, epistemological, cultural and social changes, from the realization of the roundness of the Earth to all the natural and human catastrophes. It represents universal values, valid in Africa and in America, true a hundred years ago and now, this is, valid throughout different periods of history. The text has been strong and valuable enough to dodge and transcend the historical circumstances in which it was conceived. Likewise, in an article like this it must be analyzed as independent even from the author; this article does not study Dante's intention, whether it was his real name or not, as much as it does not care about Freudian complex or his nightmares. It is irrelevant whether he loved Beatrice or Helena, or whether this book was written for them. This attitude is not born from arrogance or disrespect, but rather from the consideration that it is not possible to verify or confirm almost anything related to the text's process of creation, as history books and biographical data are never free of passion and commitment, of literature and opinion. On the other hand, the author's intention is not relevant, as there are many cases where what he actually wanted to say is not reflected in the text. Dante's economy and theoretical devices are admirable, but beyond that, it cannot be said, that this article gets even close to what Dante planned. The only thing that can be claimed is that the text allowed us to develop these interpretations, as in most cases the work develops in such a way that it overcomes the boundaries set by the author in his/her context, freeing itself and soaring away from intentionality as each reader inflates it with his/her own discourses. What really matters is the product, is what the text says and not what the author wanted to say; the interpretations made in 1500 must be different from those made nowadays, because it is interpreted by the adulterated minds of the quotidian world, but the book is still the same. In other words, the form a text adopts in the collective mind changes with each new re-visitation from different media or cultural standpoint; coexists with new art forms 
and discourses, all immersed in the ever changing flow of a globalized culture that integrates the popular and the elites.

As the milestone that Dante's Divine Comedy represents in Western culture, it has become and surely it will remain one of the most explored and alluded texts of literature, being analyzed in our current social context in its relation to other textual instances from the Western canon as much as to other examples from other traditions. This process can be carried out not just from traditional forms of literature and literary criticism but from different forms of media like music in all its different genres. As this article has defended, heavy metal, specifically symphonic metal, provides an interesting and scarcely explored framework for the reading and reinvention of traditional narratives. By weaving together legends, myths, folktales and literary works from different cultures in a mythological imaginary these bands transform our views and understanding of such sources, renewing its values and discourses, and simultaneously preserving them from becoming obsolete in social terms. Thus, by combining the particularities and the tradition of two art forms, music and literature, symphonic heavy metal provides an excellent field for the study of cultural recycling, exploring universal themes or elements significant to contemporary history and society in their reflection upon mythological, classic and canonical texts. In addition it offers a medium that overcomes the limits of high culture by reaching and appealing to a wide variety of social groups, introducing and familiarizing new audiences with the rich body of Western literary tradition, securing the permanence of these narratives in the orality of contemporary music. As such an important element as music is, it is inevitable that other relevant ingredients that compound the corpus of universal culture come into contact with it and, in turn, adapt themselves to the different devices and format developed thanks to technological advancements. The emergence of new technologies has not only consolidated the road paved by music to make culture more accessible, but also has created new ways that contribute to the attractiveness of a certain theme or topic. That way, as easily as one can listen to music while working, on their way home or wherever they want to, the Arthurian world, the stories of the Templar Knights or Dante's work can be accessible from a mp3 player, a tablet or a smartphone, devices that form part of our everyday life. 


\section{Notes}

[1] First, because symbolism does not belong to the rational order and because, by being presented conceptually, it is inevitably subjected to distortion. Secondly, because symbolism is not a doctrine or method, but an art of living, a way of seeing.

\section{References}

Alighieri, Dante. (1993/2008) The Divine Comedy. (C.H. Sisson, Trans.). Oxford: Oxford University Press.

Alighieri, Dante. (1956). Divina Comedia. In Obras Completas. Madrid: Editorial Católica S. A.

Avantasia. (2001). "Serpents in Paradise". On The Metal opera Pt. I [CD]. Shwalmstadt: AFM Records.

Avantasia. (2002). "Neverland". On The Metal Opera Pt. II [CD]. Shwalmstadt: AFM Records.

Bennett, Reimer. (1989). "Music education as aesthetic education: toward the future." Music Educators Journal, 75.7

Berger Harris M. \& Del Negro, Giovanna P. (2004). Identity and Everyday Live: Essays in the Study of Folklore, Music and Popular Culture. Connecticut: Wesleyan University Press.

Blind Guardian. (1992). "The Bard's Song - In The Forest". On Somwhere Far Beyond [CD]. Shallplatten: Virgin Records.

Blind Guardian. (1995). "Mordred's Song". On Imaginations From The Other Side [CD]. Shallplatten: Virgin Records

Blind Guardian. (1998). Nightfall in Middle Earth [CD]. Shallplatten: Virgin Records. Blind Guardian. (1998). "The Battle of Bannockburn". On Knights of the Cross [CD]. Senden/Münster: GUN Records.

Blind Guardian. (1999). Excalibur [CD]. Senden/Münster: GUN Records.

Blind Guardian. (2002). A Night at the Opera [CD]. Shallplatten: Virgin Records.

Blind Guardian. (2005). Touched by the Crimson King [CD]. Hannover: SPV Records. Blind Guardian. (2006). "Fly"; "All the King's Horses". On A Twist in the Myth [CD]. Grefrath: Nuclear Blast.

Blind Guardian. (2010). War of the Thrones. On At the Edge of Time [CD]. Donzdorf: Nuclear Blast. 


\section{MONOGRÁFICO}

De Champeaux, Gérard \& Sterckx, Dom Sébastien. (1985). Introducción a los símbolos. Madrid: Ediciones Encuentro.

Demons \& Wizards. (2000). Demons \& Wizards [CD]. Hannover: SPV Records.

González Ruiz, Nicolás. (1956). Introducción general. In Dante Alighieri, Obras completas. Madrid: Editorial Católica: pp.1-16.

Grave Digger. (1996). Tunes of War [CD]. Senden/Münster: GUN Records.

Hofstadter, Douglas R. (1979). Göedel, Escher, Bach: An Eternal Golden Braid.

Penguin Books: Midlesex.

Iced Earth. (2001). “Jack"; “Jekyll and Hyde"; “Frankenstein”; “Dracula”. On Horror Show [CD]. Florida, FL0: Century Media.

Iron Maiden. (1981). "Purgatory". On Killers [CD]. London; EMI Records. 1998 Rhapsody of Fire. (2004). "Dawn of Victory"; "The Village of Dwarfs"; "Rain of a Thousand Flames". On Tales from the Emerald Sword Saga [CD]. Multiple Studios (Compilation album): Limb Music.

Sepultura. (2006). "Dark Wood of Error"; “Convicted in Life"; “City of Dis"; “False”;

"Fighting On"; "Ostia"; "Buried Words"; "Nuclear Seven"; "Repeating the Horror". On Dante XXI [CD]. Hannover: SPV Records.

Spence, Charles et al. (2013). "Looking for crossmodal correspondences between classical music and fine wine". Licensee BioMed Central Ltd. <http://ipe. sagepub.com/content/6/3/2041669515593027.full> 3 Sep 2016

Symphony X. (2002). "Inferno (Unleash the Fire)"; "Incantations of the Apprentice"; "Accolade II". On The Odyssey [CD]. New Jersey, NJ: Inside Out.

Symphony X. (2007). "Oculus ex Inferni";"Eve of Seduction". On Paradise Lost [CD]. New Jersey, NJ: Inside Out.

Symphony X. (2015). "Nevermore"; “Without You"; “Legend". On Underworld [CD]. New Jersey, NJ: Nuclear Blast.

Van Boer, Bertil H. (2012).Historical Dictionary of Music of the Classical Period. UK: Scarecrow Press.

Wright, Jeffrey E. (1992) On the Nature of Musical Experience. University Press of Colorado. 